\title{
CONDIÇÕES OBJETIVAS E INVESTIMENTOS ACADÊMICOS DOS ESTUDANTES DO ENSINO SUPERIOR
}

\author{
Daniela Maria Ferreira* \\ Maria Emília Lins e Silva*
}

RESUMO: Que condições objetivas orientam os investimentos acadêmicos dos estudantes do ensino superior? O presente artigo discute essa questão apresentando os resultados de uma análise dos recursos sociais e culturais mobilizados pelos estudantes do curso de Pedagogia na construção de suas trajetórias universitárias. As informaçóes foram obtidas por meio de um questionário aplicado a 114 estudantes em vias de conclusão do curso. $\mathrm{O}$ artigo aponta a importância da trajetória escolar pregressa dos investigados (se estudou em escolas públicas ou privadas; se conciliou ou não estudo e trabalho durante o ensino médio), a religiáo declarada pelos estudantes e o tipo de atividade remunerada realizada durante o curso de Pedagogia na constituiçáo dos diferentes percursos universitários.

Palavras-chave: Ensino superior; Camadas populares; Trabalho; Religião.

\section{HIGHER EDUCATION STUDENTS' OBJECTIVE CONDITIONS AND ACADEMIC INVESTMENT}

\begin{abstract}
Which objective conditions guide the academic investments of higher education students? This article examines this question by discussing the socio and cultural resources that undergraduate students in the Faculty of Education at a major public university in Brazil use in the construction of their college pathways. The data was obtained through a questionnaire applied to 114 seniors. The results show the importance of the previous educational trajectory (whether they studied at public or private schools; whether they worked while attending high school), the religion declared by the students and the type of job they had while attending college in shaping their academic investments.

Keywords: Higher education; Academic investment; Popular layers; Labour; Religion.
\end{abstract}

\footnotetext{
* Universidade Federal de Pernambuco, Centro de Educação, Recife, PE., Brasil. E-mail de contato: dmffr@yahoo.fr
} 


\section{CONDITIONS OBJECTIVES ET L'INVESTISSEMENT ACADÉMIQUE DES ÉTUDIANTS DE L'ENSEIGNEMENT SUPÉRIEUR}

RÉSUMÉ: Quelles sont les conditions objectives qui guident l'investissement scolaire des étudiants de l'enseignement supérieur? Cet article examine cette question en analysant les résultats d'une enquête sur les ressources sociales et culturelles mobilisées par les étudiants du cours de Pédagogie dans la construction de leur carrière universitaire. Les informations ont été obtenues à partir d'un questionnaire rempli par 114 étudiants en dernière année. Les résultats indiquent l'importance du passé scolaire des étudiants (s'ils ont étudié dans des écoles publiques ou privées; s'ils ont concilié ou non les études et le travail pendant leurs études secondaires), la religion des étudiants et le type de travail accompli pendant le cours de pédagogie dans la constitution de leur trajectoire universitaires.

Mots-clés: Enseignement supérieur; Investissement scolaire; Couches populaires; Travail; Religion.

\section{Introdução}

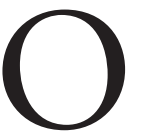

presente artigo apresenta resultados de uma pesquisa sobre os percursos universitários dos estudantes de Pedagogia da Universidade Federal de Pernambuco (UFPE), cujo objetivo é discutir as condições objetivas que orientam os investimentos acadêmicos desses jovens. Para isso, o trabalho apoiou-se em análises sobre as trajetórias dos jovens estudantes até o ingresso no ensino superior, sobre as condiçôes de sua permanência na universidade e suas perspectivas de ingresso no mercado de trabalho. Esta pesquisa pretende oferecer uma contribuição para o debate sobre os processos de ampliação das oportunidades escolares, questionando em que medida eles têm, de fato, contribuído para ampliar as oportunidades sociais dos grupos populares. ${ }^{1}$

O curso de Pedagogia é um espaço particularmente interessante para pensar as condiçóes de acesso e permanência no ensino superior, já que reúne um público bastante desfavorecido em termos de recursos sociais e culturais.

Assim, por exemplo, é no curso de Pedagogia que encontramos mais de um terço dos estudantes oriundos de escolas públicas que ingressam na UFPE. Essa situação se repete desde 2008, podendo ser considerada como um dos efeitos da implementação do Reuni ${ }^{2}$. De fato, como mostra Arruda (2011), o número de alunos de escolas públicas e com renda mensal de 1 até 2 salários mínimos aumentou 16,8\% entre os anos de 2006 (antes do Reuni) e 2010 (após o Reuni) nessa universidade. Isso não impede, no entanto, como mostra ainda a autora, que os cursos mais valorizados socialmente estejam ainda, pela maior parte, reserva- 
dos aos estudantes oriundos das escolas privadas. Ao contrário dos estudantes de escolas públicas que tendem a optar por cursos da área de Filosofia e Ciências Humanas, a presença de estudantes egressos, da escola particular é significativamente maior nos cursos de Administração, Direito, Medicina, Engenharias, Odontologia e Ciências Contábeis. Outro indicador da origem menos privilegiada dos estudantes de Pedagogia é a maior intensidade com que recebem a bolsa de manutenção acadêmica ${ }^{3}$. Das 1.712 bolsas distribuídas para os 86 cursos oferecidos pela UFPE a maior parte vai para três cursos, sendo a Pedagogia é um deles. Assim, nessa universidade, recebem bolsas: 20,2\% dos alunos do curso de Licenciatura em Geografia, 17,6\% do curso de Pedagogia e 17,5\% do curso de Serviço Social ${ }^{4}$.

Esses dados, bem como o desenvolvimento de uma literatura cada vez mais preocupada em compreender os efeitos da expansão do ensino superior no Brasil, em particular, das condiçóes objetivas de permanência no ensino superior público (VARGAS, 2011; BARBOSA, 2013; MELLO, 2004), nos levaram a tomar os estudantes do curso de Pedagogia como objeto da nossa pesquisa.

Em oposição à ideia de que as desigualdades diante da escola não podem ser reduzidas apenas às desigualdades de acesso, uma vez que elas continuam a diferenciar os estudantes dentro da própria universidade (investimentos acadêmicos, evasão, reprovação, entre outros), o presente artigo busca compreender como e de que forma os estudantes de Pedagogia vêm construindo suas respectivas trajetórias universitárias. Isso significa pensar a lógica de funcionamento do ensino superior em confluência com o resto do mundo social, e náo como um objeto autônomo, cuja finalidade encontra-se em si mesmo. Essa abordagem permite entender de que maneira os determinismos sociais, em suas dimensóes explícita e implícita (referindo-nos aos processos de socialização diretos e indiretos) que acabam por condicionar as relaçóes que os diferentes grupos sociais, travam com a cultura escolar. (BOURDIEU; PASSERON, 1964)

Mais especificamente, essa perspectiva analítica tem nos conduzido, de um lado, a considerar não apenas as demandas colocadas pelo mercado de trabalho, como, por exemplo, o aumento da demanda por mão de obra mais escolarizada (uma das consequências mais visíveis da reestruturação produtiva ocorrida nos últimos trinta anos), mas também as experiências daqueles que participam objetivamente desse espaço social, entre outros, os estudantes. Assim, se a conjuntura econômica de um determinado momento histórico é importante para pensar as demandas, expectativas e o tipo de relação que os estudantes, de maneira geral, estabelecem com o mundo universitário, é preciso não perder de vista o conjunto de propriedades sociais e culturais incorporadas pelos estudantes, as quais, transformadas em percepçóes subjetivas, acabam por orientar suas açóes ao longo de suas trajetórias escolares: da escolha do curso até a entrada no mercado de trabalho, passando pelos investimentos e apostas acadêmicas. (BOURDIEU; PASSERON, 1964) 
Longe de se constituir num bloco homogêneo, os estudantes participam, estruturam e sofrem as determinaçóes da vida universitária em função de suas histórias, que, por sua vez, são condicionadas pelas disposiçóes e orientaçóes que interiorizaram ao longo de suas trajetórias sociais. Com o intuito de compreender as diferentes maneiras de se permanecer e construir trajetória escolar, decidimos, portanto, elaborar um projeto de pesquisa que tinha por objetivo conhecer os recursos sociais e culturais mobilizados pelos estudantes de Pedagogia na construção de seus percursos universitários. Para tanto, aplicamos um questionário de caráter sociocultural aos 157 estudantes de Pedagogia que cursavam o último ano do curso $\left(9^{\circ}\right.$ e $10^{\circ}$ período), que dura cinco anos.

Todos os estudantes do curso de Pedagogia matriculados no $9^{\circ}$ e $10^{\circ}$ período do ano letivo $2012(\mathrm{n}=157)$ assistiram a uma apresentação do projeto e foram convidados a participar da pesquisa pelas pesquisadoras e bolsistas envolvidos na elaboraçáa e coordenação do mesmo ${ }^{5}$. Aplicamos o questionário nas salas de aula, gentilmente autorizados pelos professores das disciplinas e pelos próprios estudantes que se encontravam em sala. Junto com o questionário foi entregue um Termo de Consentimento Livre e Esclarecido. Dos 157 estudantes localizados, 114 responderam ao questionário; os 43 restantes náo estavam presentes em sala de aula no momento da aplicaçẫo do instrumento. Para garantir a uniformidade das condiçóes de aplicação do questionário, não oferecemos outra oportunidade a esses estudantes. Por meio desse questionário, foi possível reunir informaçóes referentes à origem sociocultural, bem como sobre o passado escolar. Além disso, foram interrogados sobre a participaçáo no conjunto das atividades extracurriculares oferecidas na própria UFPE e/ou fora dela. Consideramos como tal os programas Pibic e Monitoria, as atividades desenvolvidas junto a Grupos de Estudo e de Pesquisa, a participação em Seminários e Congressos, Diretório Acadêmico e em Projeto de extensão. Indagamos também sobre sua relação com o mundo do trabalho, por meio de questóes sobre o desenvolvimento ou náo de atividades remuneradas fora da universidade.

Os resultados oferecem indícios interessantes para compreender as formas como esses estudantes experimentam a universidade pública e, em particular, como constituem seus percursos acadêmicos durante o curso de graduaçáo. Possibilitam, ainda, aprofundar a nossa compreensão sobre a relação entre origem social e escolarização, no que diz respeito aos estudantes de origem popular.

\section{Resultados}

Majoritariamente composta por jovens do sexo feminino (dos 114 estudantes, apenas oito são do sexo masculino), a populaçáo pesquisada se constitui praticamente na primeira geração a acessar o ensino superior. A média da idade 
de entrada no curso é de 24 anos. Como mostra a Tabela 1, dos 114 estudantes analisados, em torno de um terço é oriundo de famílias em que pais e mães não finalizaram ensino fundamental. Nove entre eles são analfabetos. Os demais se distribuem entre famílias cujos pais chegaram ao ensino médio. Apenas uma minoria concluiu o ensino superior (21 pais e 21 mães).

\section{Tabela 1}

Distribuição da escolaridade dos pais dos estudantes de Pedagogia (concluintes 2012)

\begin{tabular}{c|cccc}
\hline \multirow{2}{*}{ Escolaridade } & \multicolumn{3}{|c}{ Pais } & \multicolumn{2}{c}{ Mães } \\
\cline { 2 - 5 } & Número & $\%$ & Número & $\%$ \\
\hline Analfabeto & 3 & 2,6 & 6 & 5,2 \\
Fundamental Incompleto & 37 & 32 & 34 & 30 \\
Fundamental Completo & 10 & 8,7 & 9 & 7,8 \\
Médio Incompleto & 9 & 7,8 & 8 & 7 \\
Médio Completo & 25 & 22 & 28 & 25 \\
Superior Incompleto & 8 & 7 & 8 & 7 \\
Superior Completo & 21 & 18 & 21 & 18 \\
\hline Total & 114 & 100 & 114 & 100 \\
\hline
\end{tabular}

Fonte: Questionário Sociocultural aplicado aos estudantes de Pedagogia da UFPE (concluintes 2012).

Esses resultados não diferem dos encontrados por pesquisas desenvolvidas a respeito do perfil sociocultural dos estudantes dos cursos de Licenciaturas e Pedagogia em outras universidades no Brasil. (VARGAS, 2011; NOGUEIRA, 2011; SETTON, 2002) Para além disso, as respostas ao questionário mostraram que os pais dos estudantes são oriundos de famílias com muito pouca escolarização. A maioria dos avós dos estudantes (226, num total de 228 ) não frequentou a escola e/ou eram analfabetos.

O nível de escolarização tem relação com a distribuição do tipo de ocupação dos pais dos estudantes. Podemos observar, na Tabela 2, que a grande maioria exerce atividades manuais que não exigem necessariamente uma qualificação ( $51,7 \%$ dos pais e $69,2 \%$ das mães). São essas: pedreiro, gari, segurança, pintor, costureira, empregada doméstica. Apenas nove pais e três mães desempenham atividades ligadas a profissóes liberais, que exigem diplomas (advogados e dentista, por exemplo). O restante está dividido entre as categorias ocupacionais não manuais de rotina, como, por exemplo, auxiliar da educação e vendedor, ( $14 \%$ dos pais e $12,2 \%$ das mães); as ocupaçóes técnicas e prestação de serviço que exigem uma qualificaçáo (26, 3\% dos pais e 15,7 das mães). 


\section{Tabela 2}

Distribuição das Categorias Ocupacionais dos pais dos estudantes de Pedagogia da UFPE (concluintes 2012)

\begin{tabular}{c|ccccc}
\hline Categorias & \multicolumn{3}{|c}{ Pais } & \multicolumn{3}{c}{ Mães } \\
\cline { 2 - 5 } Ocupacionais & Número & $\%$ & Número & $\%$ \\
\hline Profissionais (I +II) & 9 & 7,8 & 3 & 2,6 \\
Não Manual de Rotina & 16 & 14 & 14 & 12 \\
$\begin{array}{c}\text { Técnicos, Supervisores } \\
\text { e Trabalhadores no }\end{array}$ & 30 & 26 & 18 & 16 \\
Manual Qualificado & & & & \\
Manual não qualificado & 59 & 52 & 79 & 69 \\
\hline Total & 114 & 100 & 114 & 100 \\
\hline
\end{tabular}

Fonte: Dados obtidos por meio do questionário Sociocultural aplicados aos estudantes de Pedagogia da UFPE (concluintes 2012)

Legenda: Profissionais I e II (Ocupaçôes ligadas a profissionais liberais - médicos, advogados, dentistas etc. -, administradores e oficiais, gerentes, grandes proprietários, supervisores de trabalhadores não manuais); Não Manual de Rotina (ocupaçóes ligadas, principalmente, a escritório, trabalhadores religiosos, vendedores, oficiais de justiça, trabalhadores da educação); Técnicos, Supervisores e Trabalhadores no Manual qualificado (artesãos e trabalhadores técnicos, serviços prestados) e Manual não qualificado (trabalhadores domésticos, braçais e mal definidos), cf. GPE.

Nesse quadro de baixa escolarização dos pais e alto índice de ocupaçóes de baixo prestígio social e econômico, é possível verificar a ocorrência de algumas estratégias familiares na construção de uma escolarização diferenciada. Tal observação não difere daquelas apontadas no conjunto de trabalhos que procuram compreender como se formam os percursos escolares longevos de certos indivíduos das camadas populares. (VIANA, 2007; LACERDA, 2006; PIOTTO, 2014; ALMEIDA, 2014)

\section{Um passado escolar diferenciado: a escolha do estabelecimento de ensino e a não conciliação entre trabalho e estudo no ensino médio}

Embora um pouco mais da metade dos estudantes pesquisados tenha realizado todo ou parte de seus estudos em escolas públicas (65 e 4, respectivamente) chama atenção a proporção de estudantes que passaram pela escola particular durante o ensino fundamental e médio (45 estudantes). 
Conforme podemos observar na Tabela 3 e Tabela 4, a escolha do estabelecimento de ensino privado ou público parece manter uma relação com o nível de instrução dos pais. A escolha pelo estabelecimento de ensino privado, pelo menos para o ensino médio, por exemplo, parece se constituir uma estratégia adotada pelos familiares cujo nível de instruçáo é o maior da amostra. Dos 49 que estudaram em escolas privadas, apenas um tem a mãe analfabeta. A maior parte dos pais e mães desses estudantes concluiu o ensino médio e superior, ver Tabela 3.

\section{Tabela 3}

Relação entre o tipo de estabelecimento que frequentou durante o ensino médio e a escolaridade dos pais

\begin{tabular}{|c|c|c|c|c|}
\hline \multirow{2}{*}{$\begin{array}{c}\text { Tipo de } \\
\text { estabelecimento } \\
\text { durante o ensino } \\
\text { médio } \\
\end{array}$} & \multicolumn{2}{|c|}{ Escolaridade dos pais } & \multicolumn{2}{|c|}{ Escolaridade das mães } \\
\hline & Número & $\%$ & Número & $\%$ \\
\hline \multirow{7}{*}{ Privado } & 0 Analfabetos & 0 & 1 Analfabetas & 2 \\
\hline & $\begin{array}{l}9 \text { Fundamental } \\
\text { incompleto }\end{array}$ & 18 & $\begin{array}{l}6 \text { Fundamental } \\
\text { incompleto }\end{array}$ & 12 \\
\hline & $\begin{array}{l}4 \text { Fundamental } \\
\text { completo }\end{array}$ & 8,1 & $\begin{array}{l}3 \text { Fundamental } \\
\text { completo }\end{array}$ & 6,1 \\
\hline & $\begin{array}{l}2 \text { Médio } \\
\text { Incompleto }\end{array}$ & 4 & $\begin{array}{c}3 \text { Médio } \\
\text { Incompleto }\end{array}$ & 6,1 \\
\hline & $\begin{array}{l}10 \text { Médio } \\
\text { completo }\end{array}$ & 20 & $\begin{array}{l}15 \text { Médio } \\
\text { completo }\end{array}$ & 31 \\
\hline & $\begin{array}{l}7 \text { Superior } \\
\text { incompleto }\end{array}$ & 14 & $\begin{array}{l}7 \text { Superior } \\
\text { incompleto }\end{array}$ & 14 \\
\hline & $\begin{array}{c}17 \text { Superior } \\
\text { completo }\end{array}$ & 35 & $\begin{array}{l}14 \text { Superior } \\
\text { completo }\end{array}$ & 29 \\
\hline Total & 49 & 100 & 49 & 100 \\
\hline
\end{tabular}

Fonte: Dados obtidos por meio do questionário Sociocultural aplicado aos estudantes de Pedagogia da UFPE (concluintes 2012)

Já entre aqueles que estudaram em escolas públicas, conforme mostra a Tabela 4, verificamos que a grande maioria dos pais e mães não concluiu o ensino fundamental. Além disso, o maior número de pais analfabetos encontra-se entre os estudantes oriundos das escolas públicas. A escolha pelo tipo de estabelecimento do ensino médio guarda uma relação importante com o tipo de categoria ocupacional dos pais, conforme podemos observar na Tabela 5. É entre os pais (pai e mãe) que exercem ocupaçôes ligadas aos profissionais liberais, funcionários públicos, técnicos e prestadores de serviços que encontramos os estudantes egressos 
do ensino privado. Já dentre aqueles oriundos da escola pública, a maior parte das ocupaçóes dos pais está relacionada às profissóes do tipo manual braçal $(56,9 \%$ para pais e $69,2 \%$ para mães).

\section{Tabela 4}

Relação entre o tipo de estabelecimento que frequentou durante o ensino médio e a escolaridade dos pais

\begin{tabular}{|c|c|c|c|c|}
\hline \multirow{2}{*}{$\begin{array}{c}\text { Tipo de } \\
\text { estabelecimento } \\
\text { durante o ensino } \\
\text { médio } \\
\end{array}$} & \multicolumn{2}{|c|}{ Escolaridade dos pais } & \multicolumn{2}{|c|}{ Escolaridade das mães } \\
\hline & Número & $\%$ & Número & $\%$ \\
\hline \multirow{7}{*}{ Público } & 3 Analfabetos & 4,6 & 5 Analfabetas & 7,7 \\
\hline & $\begin{array}{l}28 \text { Fundamental } \\
\text { incompleto }\end{array}$ & 43 & $\begin{array}{l}28 \text { Fundamental } \\
\text { incompleto }\end{array}$ & 43 \\
\hline & $\begin{array}{l}6 \text { Fundamental } \\
\text { completo }\end{array}$ & 9,2 & $\begin{array}{l}6 \text { Fundamental } \\
\text { completo }\end{array}$ & 9,2 \\
\hline & $\begin{array}{l}7 \text { Médio } \\
\text { Incompleto }\end{array}$ & 11 & $\begin{array}{l}5 \text { Médio } \\
\text { Incompleto }\end{array}$ & 7,6 \\
\hline & $\begin{array}{l}15 \text { Médio } \\
\text { completo }\end{array}$ & 23 & $\begin{array}{l}13 \text { Médio } \\
\text { completo }\end{array}$ & 20 \\
\hline & $\begin{array}{l}1 \text { Superior } \\
\text { incompleto }\end{array}$ & 1,5 & $\begin{array}{l}1 \text { Superior } \\
\text { incompleto }\end{array}$ & 1,5 \\
\hline & $\begin{array}{l}4 \text { Superior } \\
\text { completo }\end{array}$ & 6,1 & $\begin{array}{l}7 \text { Superior } \\
\text { completo }\end{array}$ & 11 \\
\hline Total & 65 & 100 & 65 & 100 \\
\hline
\end{tabular}

Fonte: Dados obtidos por meio do questionário Sociocultural aplicado aos estudantes de Pedagogia da UFPE (concluintes 2012)

Questionados sobre a localização das escolas em que estudaram antes de ingressarem na UFPE, percebemos ainda que os estudantes não se diferenciam apenas em relação à/s rede/s em que completaram o ensino básico. Um outro dado interessante, embora ainda pouco explorado, diz respeito a localização das escolas na cidade do Recife e no mercado escolar pernambucano.

$\mathrm{O}$ cruzamento das informaçóes permitiu perceber que quase a metade dos estudantes oriundos de escolas da rede pública de ensino (31 dos 65), frequentou ou escolas consideradas de referência (de acordo com a classificação feita por meio do Índice de Desenvolvimento da Educação Básica - Ideb) ou escolas localizadas em bairros centrais e/ou de classe média alta. Em contrapartida, as escolas 
particulares cursadas pelos estudantes estão localizadas em bairros periféricos, na maioria dos casos no próprio bairro de residência da família do estudante.

\section{Tabela 5}

Relação entre o tipo de estabelecimento escolar durante o ensino médio e a categoria ocupacional dos pais

\begin{tabular}{c|cccccccccc}
\hline \multicolumn{1}{c}{ Estabelecimento escolar durante o ensino médio } \\
\hline $\begin{array}{c}\text { Categorias Ocupacionais } \\
\text { dos pais (EGP) }\end{array}$ & $\begin{array}{c}\text { Estabelecimento } \\
\text { Privado }\end{array}$ & \multicolumn{5}{c}{$\begin{array}{c}\text { Estabelecimento } \\
\text { público }\end{array}$} \\
\cline { 2 - 10 } & Pai & $\%$ & Mãe & $\%$ & Pai & $\%$ & Mãe & $\%$ \\
\hline $\begin{array}{c}\text { Profissionais I e II } \\
\text { Não Manual de Rotina } \\
\text { Técnicos, Supervisores e } \\
\text { Trabalhadores no Manual }\end{array}$ & 4 & 8,1 & 2 & 4,1 & 3 & 4,6 & 5 & 7,6 \\
$\begin{array}{c}\text { Qualificado } \\
\text { Manual Braçal }\end{array}$ & 8 & 16 & 11 & 22 & 3 & 4,6 & 3 & 4,6 \\
\hline Total & 17 & 31 & 6 & 12 & 22 & 34 & 12 & 18 \\
\hline & 49 & 100 & 49 & 100 & 65 & 100 & 65 & 100 \\
\hline
\end{tabular}

Fonte: Dados obtidos por meio do questionário Sociocultural aplicados aos estudantes de Pedagogia da UFPE (concluintes 2012)

No que diz respeito à relação dos estudantes investigados com o mundo do trabalho (realização de atividades remuneradas), chama atenção, a pouca conciliação entre estudo e trabalho ao longo do ensino médio.

Assim, se na geração dos avós encontra-se muito frequentemente uma precoce inserção no mercado de trabalho ou a conciliação entre trabalho e escola, situaçáo que se repete também na geração dos pais (revelada por meio da relação entre nível de escolaridade e estratos profissionais dos pais), isso parece não se estender de maneira tão intensa à trajetória social dos sujeitos investigados. Dos 114 estudantes, apenas 32 realizaram algum tipo de atividade remunerada durante o ensino médio. Os demais 82 estudantes não exerceram qualquer atividade remunerada antes de ingressar no curso de Pedagogia. Assim, diferente de seus genitores, podemos ver que boa parte dos estudantes de Pedagogia náo precisou sacrificar um dos ingredientes mais caros à incorporação do capital cultural, que é o tempo (BOURDIEU, 1998)

Mas se, num primeiro momento, o trabalho durante o processo de escolarização (anterior ao ingresso no curso de Pedagogia) não aparece como uma constante para o conjunto dos estudantes investigados, essa relação tende a se inverter na medida em que ingressam na universidade. Dos 82 estudantes que nunca 
trabalharam quando fizeram ensino médio, apenas 13 cursaram a graduação sem desenvolver qualquer atividade remunerada fora da universidade, ou seja, a maior parte dos estudantes que conciliaram estudo e trabalho ao longo do ensino médio continuou a fazê-lo durante toda a graduação. Dos 32 incluídos nesse grupo, apenas três não trabalharam ao longo da graduação. Poderíamos supor que essa inversão poderia estar relacionada com a necessidade que esses estudantes passam a ter, uma vez que já são adultos, em colaborar na renda familiar, bem como de sustentar o deslocamento diário para a universidade (tendo em vista que a maioria mora em bairros localizados nos subúrbios do Recife), em realizar as refeiçóes fora de suas residências e na compra de material (livros, xerox etc.). Vale salientar que a conciliação entre curso de graduação e trabalho acontece para todo o grupo, independentemente, por exemplo, do turno em que os indivíduos estudam (diurno ou noturno).

\section{A religião declarada pelos estudantes do curso de Pedagogia e investimentos acadêmicos}

Além de se diferenciarem com relação ao tipo de estabelecimento de ensino (privado ou público) e ao fato de terem ou não conciliado estudo e trabalho ao longo da escolarização básica, outro dado que se constitui importante para compreendermos os diferentes recursos sociais e culturais que parecem pesar na trajetória universitária dos estudantes de Pedagogia é a religiâo declarada por eles. $\mathrm{O}$ intuito de questionar os estudantes sobre este quesito diz respeito à necessidade de identificar a existência de elementos mediadores na constituição do capital cultural para além da família e escola. Evidentemente que o material coletado por meio de um questionário não nos permite, por exemplo, analisar profundamente os processos de socialização vivenciados pelos estudantes em determinados espaços religiosos e verificar sua relação com a constituição de um habitus mais favorável ao jogo escolar, conforme algumas pesquisas têm nos mostrado. (TEIXEIRA, 2013; SETTON, 2008)

No entanto, a introdução da variável religião no conjunto das propriedades sociais e culturais apresentadas sugere uma oposição interessante entre os estudantes de Pedagogia, sobretudo, no que diz respeito à intensidade e ao tipo de investimento acadêmico ${ }^{6}$ realizado pelos indivíduos ao longo da graduação.

Dos 87 estudantes que declararam uma religião, todos realizaram pelo menos uma atividade extracurricular ao longo do curso. Isso contrasta com a situação dos estudantes que declararam "não ter" uma religião. Entre esses, que totalizam 27 indivíduos, apenas cinco realizaram atividades e não mais do que uma. A religiấo indicada não parece ter um efeito sobre a intensidade das atividades extracurriculares desenvolvidas. Dos 41 estudantes que declararam ser evangélicos, 
todos realizaram pelo menos uma atividade extracurricular. Desses, 29 realizaram entre duas e quatro atividades, ao passo que os demais (12) realizaram apenas uma atividade. Entre os 37 estudantes que se declararam católicos, 29 realizaram pelo menos duas atividades extracurriculares e oito realizaram uma atividade. Dos seis estudantes que se declararam espíritas, três realizaram pelo menos duas atividades durante a graduação. Os que declaram ter religiáo (três estudantes), mas não a especificaram, realizaram pelo menos uma atividade durante o curso.

Se considerarmos o tipo de atividade extracurricular realizada pelo conjunto de estudantes que declararam ter uma religiáo, podemos perceber que entre os católicos e evangélicos encontramos as atividades extracurriculares consideradas de maior prestígio acadêmico. Os católicos, basicamente, realizaram atividades de iniciação científica/Pibic $(n=15)$, monitoria $(n=13)$ e grupo de estudo $(n=16)$. Entre os 13 que se declararam evangélicos protestantes, por exemplo, pelo menos oito fizeram iniciação científica e sete conciliaram essa atividade com monitoria. Em oposição, os cinco que declararam não ter religião, mas que realizaram alguma atividade ao longo de toda a graduação, o fizeram apenas como ouvinte em seminários/colóquios realizados, em sua grande maioria, na própria Universidade.

Embora as observaçôes acima não nos permitam pensar a religião declarada pelos estudantes como uma variável decisiva para entendermos as diferentes trajetórias universitárias da amostra analisada, parece razoável supor que essa variável se constitui, mesmo que de maneira indireta, em um aspecto importante para pensarmos a relação entre a origem social dos estudantes e os investimentos educativos realizados ao longo do percurso no curso de Pedagogia. Além disso, conforme alguns estudos vêm demonstrando (BÔAS, 2003; NOGUEIRA; CANAAN, 2009), a participação em determinadas atividades extracurriculares, a exemplo da participação no Programa de Iniciação Científica (Pibic), Monitoria e Grupo de Pesquisas, parece favorecer uma aproximação de estudantes de origem popular no universo da cultura acadêmica. Nesse sentido, identificar a religião declarada pelo estudante e sua relação, mesmo que indireta, com a realização maior ou menor de atividades extracurriculares, nos ajuda a pensar também nas condiçôes de permanência dos estudantes de Pedagogia na UFPE.

\section{Atividades remuneradas ao longo do curso de Graduação e investimentos acadêmicos}

Um outro aspecto que parece influenciar a construção das trajetórias universitárias dos estudantes de Pedagogia é o fato de eles terem exercido ou não alguma atividade remunerada em espaços educacionais ao longo do curso. Se algumas pesquisas mostram que conciliar trabalho e estudo durante a realização do curso de graduação se constitui em um dos principais empecilhos para 
a permanência na universidade e para a realização de atividades de estudo (não apenas o cumprimento da grade curricular obrigatória do curso como também a realização de atividades extracurriculares) (VARGAS; PAULA, 2008), uma análise um pouco mais cuidadosa sobre a natureza dessas atividades remuneradas parece sugerir efeitos positivos na construção da trajetória universitária dos estudantes investigados.

Assim, dos 92 indivíduos que realizaram pelo menos um tipo de atividade extracurricular ao longo de todo o curso, 79 desempenharam atividades remuneradas relacionadas à educação. Essas atividades são, na sua grande maioria, compostas por estágios não obrigatórios (37 de 79) e/ou postos de trabalho em escolas municipais, creches, além de aulas particulares (42 de 79). Esses 79 estudantes são exatamente aqueles que mais realizaram atividades extracurriculares ao longo da graduação (entre 4 e 2 atividades extracurriculares). Os demais estudantes $(n=13)$, que realizaram apenas uma atividade extracurricular ao longo do curso universitário, desenvolveram atividades remuneradas em funções e/ou ocupaçóes em espaços não escolares, como, por exemplo, em call centers ou em shoppings, como vendedoras.

Nesse sentido, esses dados parecem apoiar a hipótese de que, a depender do tipo de atividade remunerada desempenhada em paralelo ao curso de graduação, a conciliação entre trabalho e estudo possa se constituir em relação interessante náo apenas para entendermos a permanência do estudante-trabalhador e de baixa renda na universidade, como também a construção de seu percurso universitário.

\section{Para seguir pensando}

A sistematização dos dados expostos ao longo deste trabalho indica pistas interessantes a serem perseguidas e aprofundadas em novas investigaçóes. Fica claro que a permanência dos estudantes de Pedagogia na UFPE e o tipo de percurso universitário traçado por eles durante os cinco anos de Graduação tendem a se diferenciar em função dos diferentes fatores associados aos seus perfis e trajetórias escolares e sociais.

O tamanho, relativamente pequeno, da amostra e o fato de termos realizado até o momento apenas análises estatísticas não nos permitem tecer generalizaçóes a respeito da permanência dos estudantes de baixa renda e do tipo de investimento acadêmico feito por eles.

Chama atenção, em todo caso, a possibilidade e a importância do estudo de maneira mais complexa sobre os processos sociais que direcionam indivíduos de origem social semelhante à construção de diferentes percursos universitários. No grupo analisado, esses processos variam conforme a trajetória escolar anterior 
dos investigados (escolas públicas ou privadas; se conciliou ou não estudo e trabalho durante o ensino médio), o perfil social dos familiares (aqui objetivados pela escolaridade e profissão dos pais/mães), a religião declarada pelos estudantes e o tipo de atividade remunerada realizada durante o curso de Pedagogia, entre outros fatores.

Nesse sentido, acreditamos ser importante a construção de indicadores que nos ajudem a problematizar a relação já existente, e fartamente constatada pela literatura sociológica, entre condiçôes socioeconômicas e escolarização.

\section{Notas}

1. Agradecemos a todos os estudantes do curso de Pedagogia da UFPE pela disponibilidade e confiança necessárias a realização da presente pesquisa. Um muito obrigado especial a todas as bolsistas do Gepfep envolvidas diretamente no trabalho de coleta e sistematizaçáo dos dados, que deram origem aos primeiros resultados de pesquisa apresentados nesse artigo.

2. O Programa de Apoio a Planos de Reestruturação e Expansão das Universidades Federais (ReUni), implementado pelo Ministério da Educação, visa ao acesso e à permanência de estudantes de origem menos privilegiada na educação superior pública. Para tanto, todas as universidades federais foram instadas a aderir ao programa e apresentar ao Ministério planos de reestruturaçáo que previam, além de aumento de vagas, a ampliação ou abertura de cursos noturnos, o aumento do número de alunos por professor, a redução do custo por aluno, a flexibilizaçáo de currículos e o combate à evasão. Em contrapartida, elas receberiam recursos significativos para custear sua expansão e outros projetos.

3. Essa bolsa, no valor de $\mathrm{R} \$ 365,00$, concedida pela Pró-reitoria para Assuntos Estudantis (Proaes) da UFPE, tem por objetivo custear a permanência do estudante na universidade. Ao recebê-la, o estudante se compromete a desenvolver 12 horas semanais de atividade em algum dos diferentes espaços da universidade: da biblioteca até os setores administrativos, passando pelos grupos de pesquisa. A bolsa é oferecida em funçáo da situação socioeconômica dos estudantes. Requer-se renda familiar de até um salário mínimo e meio per capita, com prioridade para os estudantes que tenham cursado a educaçáo básica em escola pública.

4. Dados obtidos na Pró-reitoria para Assuntos Estudantis (Proaes) da Universidade Federal de Pernambuco relativo ao ano acadêmico de 2014.

5. A pesquisa, intitulada "Percursos universitários dos estudantes de Pedagogia da UFPE", está sendo desenvolvida pelo Grupo de Estudo e Pesquisa Família, Escola e Profissão (GEPFEP), do Centro de Educação da Universidade Federal de Pernambuco.

6. Conforme já sinalizado, os investimentos acadêmicos estão sendo objetivados, na presente pesquisa por meio de indicadores como: participação ou não no conjunto de atividades extracurriculares oferecidas na própria universidade, a saber: a participação em grupos de pesquisas, a realização de uma iniciação científica ou de uma monitoria, participação em projetos de extensão, em congressos e simpósios e diretório acadêmico.

\section{Referências}

ALMEIDA, W. M. Estudantes com desvantagens sociais e os desafios da permanência na universidade pública. In: PIOTTO, D. (Org.). Camadas Populares e universidades públicas: trajetórias e experiências escolares. São Carlos: Pedro \& João Editores, 2014, p. 275-312. 
ARRUDA, A. B. Expansão da Educação Superior: uma análise do Programa de Apoio a Planos de Reestruturação e Expansão das Universidades Federais (Reuni) na Universidade Federal de Pernambuco. Tese de Doutorado. Programa de Pós-Graduação, Universidade Federal de Pernambuco, 2011.

BARBOSA, M. L. O. (Org.) Ensino Superior: expansão e democratização. Rio de Janeiro: 7Letras, 2014.

BAUDELOT, C. As Qualificaçóes aumentam, mas a desigualdade torna-se ainda maior. Proposiçóes, v.15, n.2 (44), p.15-38, maio/ago., 2004.

VILLAS BÔAS, G. K. Currículo, iniciação científica e evasão de estudantes de Ciências Sociais. Tempo Social, São Paulo, v. 15, n.1, p. 45-62, 2003.

BOURDiEU, P.; CATANI, A. M.; NOGUEIRA, M. A. (Org.). Escritos de educação. 10. ed. Petrópolis: Vozes, 2008.

BOURDIEU, P.; PASSERON, J.-C. Les héritiers: les étudiants et la culture. Paris: Les Éditions de Minuit, 1964.

LACERDA, W. M. G. Solidariedade entre irmãos e relaçóes intergeracionais na construção de percursos escolares de excelência. Educação em Perspectiva, v. 1, p. 83-102, 2010.

MELLO, J. C. Desigualdades Sociais e Acesso ao Ensino Superior no Brasil no período 1994-2001. Revista electrónica iberoamericana sobre calidad, eficacia y cambio en educación, Madrid, v. 5, n. 2, p. 69-83, 2007.

NOGUEIRA, M. A.; CANNAN, M. Os iniciados: os bolsistas de IC e suas trajetórias acadêmicas. Tomo (UFS), v. 15, p. 41-70, 2009.

PIOTTO, D. C. (Org.) Camadas Populares e Universidades Públicas. Trajetórias e experiências escolares. São Carlos: Pedro \& Joao Editores, 2014.

POCHMANN, M. Trabalho e Formação. Educação e Realidade, v. 37, p. 337-708, 2012. . Reestruturação Econômica e Formação para o trabalho. Revista Latinoamericana de Estudios del Trabajo, v. 5, p. 135-152, 2011.

SETTON, M. G. J. A divisão interna do campo universitário: uma tentativa de classificação. Revista Brasileira de Estudos Pedagógicos, Brasília, v. 80, n. 196, p. 451-471, 2002.

. As religióes como agentes de socialização. Cadernos CERU, São Paulo, série 2, v. 19, n. 2, p. 15-25, dez. 2008.

SILVA, M. A. O perfil socioeconômico e cultural dos estudantes dos cursos de licenciaturas diversas do Centro de Educação da UFPE. Projeto de Iniciação Cientifica (PIBIC), orientado pela Profa. Dra. Maria Emília Lins e Silva, 2013.

TEIXEIRA, A. D. F. Jovens pobres e ensino superior: um estudo sobre os processos de socialização nos grupos religiosos UFMG - Universidade Federal de Minas Gerais, 2011. Disponível em: <http://www.sistemasmart.com.br/alas/arquivos/alas_GT25_Anna_ Donato_Gomes_Teixeira.pdf>. Acesso em 10/04/2013. 
VARGAS, H. M. Organizando a desigualdade social: o papel do ensino superior. In: CONGRESSO INTERNACIONAL DA ALAS, 28., 2011, Recife. Anais... Recife: ALAS, 2011.

VARGAS, H. M.; PAULA, M. de F. C. de. A inclusão do estudante-trabalhador e do trabalhador-estudante na educação superior: desafio público a ser enfrentado. Avaliação, Campinas; Sorocaba, SP, v. 18, n. 2, p. 459-485, jul. 2013.

VIANA, M. J. B. Longevidade escolar em famílias populares: algumas condiçôes de possibilidade. Goiânia: Ed. da UGC, 2007.

Recebido em 26 de agosto de 2014.

Aprovado em 09 de março de 2015. 